We appreciate the response to this publication feature - and weicome all contributions. Contributions may be sent to Phil Oshel, our Technical Editor at:

$\begin{array}{ll}\text { Mr. Phil Oshel } & \text { (608)833-2885 } \\ \text { PO Box 620068 } & \text { eMail: oshel@terracom.net } \\ \text { Middleton W/ } 53562 & \end{array}$

\title{
Visualizing Capillary Beds
}

Standard methods of visualizing capillary beds in tissue often require perfusing the capillaries with colored markers such as India ink or casting materials. The specimen material is subject to substantial artifact from incomplete perfusion and distortion of delicate vascular components due to excessive perfusion pressure.

A simple method to minimize these potential problems uses the blood components in unperfused tissue. The endogenous peroxidase in red blood cells is easily reduced in the presence of hydrogen peroxide with the resultant oxidation of the chromagen 3,3'-diaminobenzidine (DAB) and formation of a dark reaction product throughout the vasculature. Exposing the tissue sections to peroxidase-conjugated $\mathrm{lgG}$ to enhance background staining can further enhance the reaction.

The procedure is as follows:

1) Cool the tissue immediately after euthanizing the animal or removing the organ in order to promote blood clotting.

2) After 1 to 2 hours, cut the tissue into $1 \mathrm{~cm}^{2}$ blocks, immerse in cold $4 \%$ paraformaldehyde in $0.1 \mathrm{M}$ Phosphate buffer $(\mathrm{pH} 7.2$ to 7.4$)$ and fix for 24 to 48 hours at $40^{\circ} \mathrm{C}$.

3) Wash with buffer to remove excess fixative and cut on a vibrating microtome in 50 to $60 \mu \mathrm{m}$ sections.

4) Immerse sections in a $0.02 \%(W / V)$ solution of $3,3^{2}$ diaminobenzidine (DAB) containing $0.03 \% \mathrm{H}_{2} \mathrm{O}_{2}$ for 15 to 30 minutes at room temperature.

5) The reaction may be amplified by incubating the tissue sections in a 1:100 (vol/vol) dilution of peroxidase-conjugated goat anti-rat (or appropriate species depending on your tissue). IgG in $0.02 \mathrm{M}$ phosphate buffer for 30 minutes at room temperature. Wash sections three times for 15 minutes to remove unbound $\operatorname{lgG}$ and react with $\mathrm{DAB}-\mathrm{H}_{2} \mathrm{O}_{2}$ developing solution as above.

DAB- $\mathrm{H} 202$ defined microangiograms can be digitized and vessels quantified using image analysis programs. Three-dimensional reconstruction of serial sections can be produced and parameters such as volume density calculated.

The major source of artifact in this method is shrinkage associated with aldehyde fixation. Shrinkage can be limited by using freshly prepared fixatives and standard block sizes and fixation times. Estimates of shrinkage can then be taken into account when analyzing and quantitating microvasculature.

Additional details and illustrations are found in: Sherman, 9. and W. Paull (1985). New Method for Visualization of Vascular Networks in Nonperfused Fixed Tissues. Stain Technology. 60:2 p.89.

$$
\text { Debby Sherman, Purdue University }
$$

\section{A Note on Solvents for Embedding with Epon}

John Luft originally suggested 1-2 epoxy propane or propylene oxide as an intermediate solvent for epoxy infiltration because he reasoned that its chemical structure would allow it to be incorporated into the epoxy resin.

But I question if this could ever happen. Consider the boiling points of the three solvents which are being compared:

$\begin{array}{ll}\text { ethanol. .......... } & 78.3^{\circ} \mathrm{C} \\ \text { acetone. ........ } & 56^{\circ} \mathrm{C} \\ \text { epoxy propane... } & 34.3^{\circ} \mathrm{C}\end{array}$

Most epoxies are cured at $70^{\circ} \mathrm{C}$ or above. At this temperature acetone and especially epoxy propane will very rapidly evaporate from the mixture. But alcohol will not. Years back, I mixed epoxy resin with ten percent of each solvent, and put the three samples into the curing oven at $70^{\circ} \mathrm{C}$. The acetone an epoxy propane mixtures cured perfectly normally, but the alcohol sample stayed sticky. I think it just doesn't evaporate.

Bottom line: since then my lab has always used acetone as a less hazardous alternative to epoxy propane. They both reduce the viscosity of epoxy resin about the same amount. The historically minded could check my 1968 paper, "viscosity changes in Araldite during polymerization", Laboratory Practice 17:707-708.

Mel Dickson, University of New South Wales, Australia

\section{A Blocking Agent for Endogenous Peroxide}

We have used $0.1 \%$ sodium azide $+3 \%$ hydrogen peroxide for many years without damage to acetone-fixed frozen sections. This blocking protocol will work with almost all slide-based specimens for blocking endogenous peroxidase.

The $0.1 \%$ sodium azide solution is prepared as a stock solution and the hydrogen peroxide is added prior to use (within several hours). Azide stock is stable for 2 months and a $10 \mathrm{X}$ (or $1 \%$ ) solution can be made if large volumes are used.

The following mix is used for 10 minutes at room temperature after rehydrating slides following fixation in acetone:

$0-1 \%$ sodium azide $45 \mathrm{~mL}$

$0.3 \%$ hydrogen peroxide $5 \mathrm{~mL}$

(use $3 \%$ hydrogen peroxide for peripheral blood smears)

Discard azide solutions according to waste management practice at your institution.

This method is adapted from the method in: $\mathrm{Li}_{i}$ C. Y., S.C. Ziesmer, and 0. Lazcano-Villareal. 1987. Use of azide and hydrogen peroxide as an inhibitor for endogenous peroxidase in the immunoperoxidase method. Journal of Histochemistry \& Cytochemistry. 35(12):1457-60.

Timothy Plummer, Mayo Clinic, Rochester. Minnesota

\section{To Obtain Vertical Sections of Cell Monolayers for TEM}

Our cell monolayers were positioned on the very edge of our specimen blocks. Upon sectioning and mounting, the ultra-thin sections folded over, hammering TEM examination of the cell monolayers. The following soda-straw method centered the monolayers on the specimen blocks and solved our problem:

1) Embed the monolayer within the culture dish with Polybed 812.

2) Following heat polynienzation, use a hammer to extract the sample from the dish.

3) Secure the disk-shaped sample in a vise and with a jeweler's or coping 